\title{
Fruit and vegetable intake of schoolchildren in Quetzaltenango, Guatemala
}

\author{
Gabriela Montenegro-Bethancourt, ${ }^{1}$ Colleen M. Doak, ${ }^{2}$ \\ and Noel Solomons ${ }^{1}$
}

Suggested citation

Montenegro-Bethancourt G, Doak CM, Solomons N. Fruit and vegetable intake of schoolchildren in Quetzaltenango, Guatemala. Rev Panam Salud Publica. 2009;25(2):146-56.

ABSTRACT Objective. To determine if fruit and vegetable consumption among high-and low-socioeconomic status (HSES-LSES) urban schoolchildren in Quetzaltenango, Guatemala, was adequate according to World Health Organization (WHO) recommendations.

Methods. Cross-sectional data from 449 third-and fourth-grade girls and boys from $12 \mathrm{el}$ ementary schools were collected, analyzed, and presented by socioeconomic status and gender. Public schoolchildren were classified as LSES $(\mathrm{n}=219)$ and private schoolchildren were classified as HSES $(\mathrm{n}=230)$. Dietary fruit/vegetable intake of each student was determined based on a 24-hour recall pictorial record and personal interview. All food items containing fruits or vegetables (including beverages) were classified and tabulated. Frequency of fruit/vegetable intake was calculated based on "mentions" (number of times a fruit or vegetable item was reportedly consumed), and nutritional adequacy was assessed for each group by mean and median values and compared to WHO daily recommended fruit/vegetable intake (400 g). Based on World Cancer Research Fund (WCRF) exclusion guidelines, the fruit/vegetable contribution to total energy was estimated.

Results. Of the 247 different food items identified, 93 (37.7\%) contained a fruit or vegetable. Total food mentions ( $\mathrm{n}=6512$ ) included 637 fruit items and 701 vegetable items. Although mean fruit/vegetable intake in grams was 461.3 (standard deviation, \pm 332.5 ), more than half $(56.3 \%)$ of the subjects fell below the 400-g recommended daily level. Estimated fruit/vegetable contribution to total energy was $21.2 \%$ for HSES and $19.1 \%$ for LSES.

Conclusion. This study revealed inadequate fruit/vegetable intake among the study sample. For compliance with global recommendations, interventions promoting fruit/ vegetable intake are needed.

Key words Fruit; vegetables; nutrition policy; nutrition assessment; nutrition, public health; child nutrition; Guatemala.

Diverse epidemiological evidence has indicated an inverse association between

1 Center for Studies of Sensory Impairment, Aging and Metabolism (CeSSIAM), Guatemala City, Guatemala.

2 Institute of Health Sciences, Vrije University Amsterdam, Amsterdam, The Netherlands. Send correspondence and reprint requests to: Colleen Doak, Institute of Health Sciences, Vrije University Amsterdam, De Boelelaan 1083, Amsterdam $1081 \mathrm{HV}$, The Netherlands; telephone: +31 (20) 598 3502; fax: +31 (20) 598 6940; e-mail: colleen.doak@falw.vu.nl the risk of hypertension, vascular diseases and stroke (1), obesity (2-4), and various cancers $(5,6)$ and the consumption of fruit and vegetables. To promote increased consumption of these foods, the World Health Organization (WHO) recommends a daily intake of $400 \mathrm{~g}$ of fruit and vegetables in its guidelines for healthy eating (7).

Research indicates that food-related preferences and practices are formed in the earliest years of life (8), and eating fruit and vegetables at a young age can influence intake patterns in adulthood (9-11). Recent surveys suggest a large majority of schoolchildren in different regions of the world are not eating fruits or vegetables every day (11-13). Research on the effect of gender on fruit/ vegetable consumption has produced mixed results: two studies suggest that girls are more likely than boys to con- 
sume fruit and vegetables $(9,14)$, whereas another study finds no difference according to gender (15). More information is needed to determine if gender is an important factor in fruit and vegetable intake among children. Low socioeconomic status (LSES) has also been associated with low consumption of fruit and vegetables $(8,16-21)$.

Guatemala has been described as a country with a high proportion of its population reliant on foods of plant origin due to the emphasis on fruits and vegetables in the traditional diet $(22,23)$. The plant sources of foods consumed by children, however, have not been specified. To generate information on fruit/ vegetable consumption among children, a survey of self-reported food and beverage intake was conducted among third- and fourth-grade schoolchildren in the western highland city of Quetzaltenango, Guatemala, using an innovative pictorial-record method. This study assesses the contribution of fruit and vegetables as a percentage of the total selfreported food intake. An urban setting was chosen for the study to allow for better understanding of the early stages of the nutrition transition outside the sphere of influence of modernization that prevails in the nation's capital. The study aimed to determine if fruit and vegetable consumption among highand low-income Quetzaltenango urban schoolchildren was adequate according to WHO recommendations of daily intake for boys and girls.

\section{MATERIALS AND METHODS}

\section{Population}

A total of 449 boys and girls attending third and fourth grade were recruited to participate in the study. The study results for LSES (low-socioeconomic status) children are based on 219 students from five public schools, whereas those for high socioeconomic status (HSES) children are based on 230 students from seven private schools.

\section{Study sites}

The study was conducted in the urban area of Quetzaltenango, the secondlargest city in Guatemala, with an area of $203 \mathrm{~km}^{2}$ and 106528 inhabitants, located $210 \mathrm{~km}$ southwest of the capital of Guatemala City. The study protocol was ap- proved by the Human Ethics Committee of CeSSIAM (Center for Studies of Sensory Impairment, Aging and Metabolism) and was also presented to local education authorities to obtain their authorization of the study. Local education authorities provided the official list of all urban elementary schools in Quetzaltenango, and prestigious private schools and various public schools were identified and selected as the source for HSES and LSES study participants, respectively. The use of school type as a proxy for family economic status was justified based on the disparity of cost for educating one school-aged child in the city, which ranged from 0 for the public schools to US \$60-\$120 (or 8-15\% of median local household income, respectively) for private schools. In order to capture roughly equal numbers of LSES and HSES students, school selection was based on enrollment size. Out of 16 public and private schools invited to participate in the study, 12 agreed to participate.

\section{Data collection}

The fieldwork was conducted from April to June 2005. Researchers met with local school authorities to introduce the project and seek input and cooperation. Participating schools were given a copy of the protocol, the consent forms, the data collection schedule, and an agreement letter in which the researchers agreed to provide the study results on nutritional status, and general nutritional recommendations, to both the schools and individual children. During class time, the principal investigator explained the study protocol and distributed written consent forms to all students in third and fourth grade. The teachers were asked to collect all consent forms signed by legal guardians. The signed consent forms were collected two days before the scheduled interviews with the children to allow researchers to estimate the total number of participants and to provide the students who had not yet supplied a consent form with a second opportunity to meet that requirement and participate in the study.

Dietary intake information. Both the instrument and the methodology used for data collection for this study were previously used in studies conducted among urban schoolchildren in Guatemala City (C. Pinneta and L. Hernandez, CeSSIAM, personal communication, 8 November 2004). Data were collected during regular school hours (i.e., Monday through Friday, excluding holidays). The data collection instrument consisted of a five-page booklet designed to capture study participants' recall of their total food consumption (including beverages) over a 24-hour period. The first page of the booklet included written instructions on how to complete the questionnaire. The next three pages included space for the students to record their food intake during the three main meals of one 24-hour period and were labeled "breakfast," "lunch," and "dinner," respectively. The fifth page included space for recording all consumed foods not perceived as part of any of the three main meals and was labeled "snacks."

During class, the data collection booklets and a set of crayons were given to each of the study participants, who were asked to take the booklets home; draw a picture of all food items they had consumed since their last meal and for 24 hours thereafter, both at school and at home (including candy); and specify the brand names and amounts consumed.

On the following day, the subjects were interviewed face-to-face by the principal investigator, assisted by two second-year nutrition students from a local university who were trained in the interview method. The interview allowed the investigators to confirm the type of foods drawn by the children and to estimate the portions, using food models and common household measures. Children who had forgotten to bring their booklet were given a new one and asked to record their food intake for the subsequent 24-hour period, and the interview was postponed to the following day. Children who were absent on the day of the interview were excluded from the study.

\section{Classification of food groups and food and beverage items}

Both descriptive and quantitative approaches were used to determine the number and type of different food items consumed by study participants over the 24-hour evaluation period, as well as the form and preparation of each item. To determine the total number of different foods consumed, each item was coded and enumerated individually (e.g., one unit of processed fruit juice would be 
classified as a unique item, under its respective brand name, and assigned a number). Each individual food item (which corresponded to a unique code) was then added to the total "number of items," resulting in a total of 247 different food items. After coding and classifying each different type of food item consumed, investigators tabulated the total number of "mentions" of fruit and vegetable items combined (i.e., the number of times a food or beverage containing a fruit or vegetable was reportedly consumed), and the total number of mentions of fruit versus vegetable items. The results (i.e., the total daily intake of fruit and vegetables) were presented as a percentage of the total number of food items consumed among the third- and fourth-grade students, by socioeconomic group and gender.

Due to ongoing controversy over universal definitions of food groups (24), this study based its classification of fruit and vegetables on cultural and culinary use of foods (i.e., the common forms in which fruit and vegetables are consumed in Quetzaltenango). Food items classified as "fruit" included those containing any type of fruit in its whole, juiced, or liquefied form, as well as any recipe components (natural or processed) containing fruit. Plant-based foods such as cereal grains, pulses (edible seeds of various legumes), and nuts, and plant products such as coffee, tea, and chocolate, were excluded from the "fruit" category, whereas fruit jelly (usually classified as "sweets") and fruit-based commercial drinks were included. Items classified as "vegetables" included edible parts of plants commonly considered vegetables (e.g., corn eaten from the cob, or "whole," versus cornmeal in dough, which was treated as a cereal). In this study, food items containing both common forms of avocado (raw, or pureed, as in guacamole) were classified as "vegetables" rather than "fruit" due to cultural perceptions in Guatemala. Food items containing tomato were also categorized as "vegetables," based on its use in Guatemala, where it is widely consumed in different forms. Despite their tomato component, ketchup and tomato paste were not categorized as vegetable items (but were included in study tabulations of total food items consumed). As mentioned above, pulses were generally excluded from the "fruit" category, except for immature pulses such as fresh green peas, which were included. Potato was classified as a vegetable due to cultural perceptions in Guatemala.

\section{Fruit and vegetable intake}

Form/preparation. Food items primarily classified as "fruit" or "vegetables" were further categorized according to their form of preparation or consumption. Six subcategories were created for fruit items: (1) "raw, served alone" (i.e., fruits consumed whole); (2) "raw, in recipes" (e.g., processed or natural fruits in a fruit salad); (3) "cooked, served alone" (e.g., fruits cooked or fried in oil, such as fried plantain); (4) "juices" in multiple forms (e.g., pure, natural fruit extract as well as commercially processed fruit juices); (5) "liquefied" (i.e., any fruit mixed with water or some other liquid, with or without sugar, but with no industrial processing); and (6) "miscellaneous" (i.e., alternative fruit presentations, such as popsicles or iced natural fruit, and other foods containing fruits that did not fit into the five categories above).

A similar classification system was used for vegetables. The category "raw, served alone or in recipes such as salad" included vegetables not exposed to any thermal process (e.g., cucumber). The "cooked, served alone" vegetable category included items defined in a manner similar to the one stated above for fruits (i.e., foods with vegetables as the primary ingredient, allowing for the use of oil in the cooking process). The definition for the "cooked in combination recipes" category was similar to that for the "raw, in recipes" category for fruits (i.e., all food mixtures or recipes containing vegetables). The "juices" and "liquefied" vegetable categories were also similar to those for fruits, while the "miscellaneous" category included foods containing vegetables in a very small quantity (e.g., garnishes).

Frequency by item. The frequency of fruit/vegetable intake was calculated according to the total number of mentions of fruit and vegetable food items, which were tabulated as follows: (1) a list of total disaggregated food items was created, as described above; (2) the total number of mentions for each specific food item was determined; (3) all food items containing a fruit or vegetable were classified into primary categories as "fruit" or "vegetables"; (4) the total number of mentions for each different fruit and vegetable item was calculated; (5) the total number of mentions (i.e., the frequency of consumption) of all fruit and vegetable items was calculated, pooling the results from all study participants; (6) using this method, the top 15 most frequently mentioned food items in the "fruit" category and the top 15 most frequently mentioned food items in the "vegetables" category were identified; and (7) based on total mentions of all fruit- and vegetable-containing food items (versus total mentions of all food items) the proportion of fruit/ vegetable intake relative to total food intake was calculated. These results were presented in an aggregate form as well as by socioeconomic class (private or HSES schoolchildren versus public or LSES schoolchildren) and gender.

Frequency by study participant. Study participants were classified according to the number of mentions of fruit or vegetable items (24-hour food consumption self-reported via pictorial record and a personal interview). At an individual level, children who mentioned any fruit/vegetable consumption were classified as consumers of "fruit," "vegetables," or "fruit or vegetables." Thus, food consumption data for one child could appear in multiple categories (not including the mutually exclusive category of "no fruit or vegetables," which included only those study participants who did not report consumption of any fruit- or vegetable-containing item during the 24-hour evaluation period).

Adequacy. Adequacy of fruit/vegetable intake was determined based on the WHO recommendation of $400 \mathrm{~g}$ or more of fruit/vegetable intake daily $(7,24)$. Those consuming fruit and vegetables at the WHO-recommended level or above were categorized as having "adequate" intake, whereas those consuming less were classified as having "inadequate" intake. The reported portions of foods and beverages containing specific fruits or vegetables themselves or fruit- or vegetable-containing ingredients or components were converted from common household units into grams. Non-fruit and non-vegetable portions of mixed foods were included in the weight calculations for total grams of fruit and vegetable intake (i.e., this analysis did not disaggregate the fruit- and vegetablecontaining components of recipes or mixed foods). 
Estimated contribution to energy. The contribution of each of the main food groups (including fruit and vegetables) to average reported 24-hour energy intake was calculated. The total energy value (in kcal) of total daily food intake was determined for each respondent using the corresponding food composition table values (25). Then, using the convention described above (tabulating all items representing fruit or vegetable intake), the combined contribution of the fruit and vegetable food groups was expressed as a percentage of the total energy obtained by the individual from his/her total food intake. As in the weight calculations, non-fruit and nonvegetable portions of mixed foods were included in the calculations for total energy contributed by fruit and vegetable intake. The mean values were then computed separately by socioeconomic group and gender-specific subsample. As a variant of this energy contribution calculation, the study also presented the findings in terms of the recommendations presented in the expert panel report Food, Cancer and the Prevention of Cancer: A Global Perspective of the World Cancer Research Fund (WCRF) and its U.S. affiliate, the American Institute for Cancer Research (AICR) (6). The panel's recommendation for a public health goal at the population level is to "promote year-round consumption of a variety of vegetables and fruits, providing $7 \%$ or more total energy" (6: 512). According to the classification scheme adopted by the WCRF/ AICR, food items containing the fruit of plants from the Musa genus (including bananas and plantains) and those containing potatoes or potato-containing components are classified as starchy foods rather than "fruit" or "vegetables," respectively (6). Therefore, in the presentation of the study results based on the WCRF goals, food items containing banana and plantain are not counted as "fruit" food items and those containing potatoes are not counted as "vegetable" food items.

\section{Data handling and statistical analysis}

Frequencies and percentages and mean, standard deviation (SD), median, minimum, and maximum values were obtained for both categories of social class (LSES and HSES) and differentiated by gender. To establish differences between the two socioeconomic groups, means comparisons were conducted using the student's t-test. SPSS 12.0 (SPSS Inc., Chicago, USA) was used for data analysis.

\section{RESULTS}

Of the 1124 children invited to participate in the study (624 LSES and 500 HSES), only those with a consent form signed by a legal guardian and a completed booklet were interviewed $(n=449)$. The response rate in the LSES group was 35\%, and the final sample size was 219 (113 girls and 106 boys). The response rate in the HSES group was $46 \%$, and the final sample size was 230 (119 girls and 111 boys). The overall response rate was $40 \%$ (with similar results between boys and girls).

\section{Fruit/vegetable intake}

Form/preparation. Of the total 247 disaggregated food items, total fruit/vegetable items represented $37.7 \%(n=93)$. The total number of fruit and vegetable items mentioned by all schoolchildren (classified by form of preparation in Table 1) was $48(19.4 \%$ of all food items consumed) and $45(18.2 \%)$. Of all fruit and vegetable items reportedly consumed, $32.2 \%$ contained sugar (data not shown). This study revealed sugar was added to $54.2 \%$ of the fruit items and $8.9 \%$ of the vegetable items reportedly consumed by the study participants (including processed or packaged items

TABLE 1. Classification of fruit and vegetable items consumed by third- and fourth-grade schoolchildren in Quetzaltenango, Guatemala, by form of consumption (April-June 2005)

\begin{tabular}{|c|c|}
\hline Form of consumption & Items consumed \\
\hline \multicolumn{2}{|l|}{ Fruits (No. $=48)$} \\
\hline Raw, served alone & $\begin{array}{l}\text { Apple; banana; cantaloupe; cherries; grapes; mango; orange; papaya; peaches; pears; pineapple; prunes; raisins; } \\
\text { coconut; strawberries; watermelon; wild cherries }\end{array}$ \\
\hline Raw, in recipes & Fresh fruit salad \\
\hline Cooked, served alone & Boiled plantain; fried plantain \\
\hline Juices & $\begin{array}{l}\text { Lemon; blackberry drink; cantaloupe drink; lemonade; mango drink; natural orange juice; orangeade; papaya } \\
\text { drink; pineapple drink; star-fruit drink; tamarind drink; watermelon drink; processed juice brand D; processed juice } \\
\text { brand F, processed juice brand J; processed juice brand K }\end{array}$ \\
\hline Liquefied & Banana milk shake; plantain gruel \\
\hline Miscellaneous & $\begin{array}{l}\text { Bean-stuffed plantain; chocolate-covered banana; strawberry cake; jelly; fruit yogurt } \\
\text { Iced popsicles: blackberries; coconut; mango; pineapple; strawberry }\end{array}$ \\
\hline \multicolumn{2}{|l|}{ Vegetables (No. = 45) } \\
\hline Raw, served alone or in recipes such as salad & $\begin{array}{l}\text { Avocado (whole); carrot; celery; cucumber; guacamole (avocado paste); lettuce; "chirmol" (raw tomato sauce); } \\
\text { radish; tomato }\end{array}$ \\
\hline Cooked, served alone & $\begin{array}{l}\text { Beets; boiled potatoes; broccoli; cabbage; cauliflower; Swiss chard; chayote fruit; cooked carrot; eggplant; fried } \\
\text { potatoes (homemade or fast-food restaurant); green beans; green leafs; peas; zucchini squash; spinach; sweet } \\
\text { corn on cob }\end{array}$ \\
\hline Cooked in combination recipes & $\begin{array}{l}\text { Asparagus soup; beef and vegetables stew; chaw-mein; chicken and vegetables stew; "chipilin leaf in corn } \\
\text { tamale"; mixed vegetable salad with mayonnaise; potato salad with mayonnaise; mashed potatoes; potato dough } \\
\text { tamale, sweet red peppers }\end{array}$ \\
\hline Juices & Carrot juice \\
\hline Liquefied & Natural vegetables soup; sweet-corn gruel \\
\hline Miscellaneous & $\begin{array}{l}\text { Ketchup; pasta and tomato sauce; "pepian" (spicy tomato sauce); "recado" (tomato-based sauce); onions; raw } \\
\text { chives; mushrooms }\end{array}$ \\
\hline
\end{tabular}

Source: Authors' compilation.

a The use of italics indicates foods with added sugar or other sweeteners. 
TABLE 2. Top 15 fruit items most frequently mentioned in 24-hour dietary intake recall by third- and fourth-grade schoolchildren in Quetzaltenango, Guatemala (April-June 2005)

\begin{tabular}{|c|c|c|c|c|c|c|}
\hline \multirow[b]{2}{*}{ Rank $^{c}$} & \multicolumn{2}{|l|}{$\begin{array}{c}\text { Overall } \\
(n=449)\end{array}$} & \multicolumn{2}{|l|}{$\begin{array}{l}\text { LSES }^{a} \\
(n=219)\end{array}$} & \multicolumn{2}{|l|}{$\begin{array}{l}\text { HSES }^{\mathrm{b}} \\
(n=230)\end{array}$} \\
\hline & Fruit item & Percent $^{d}$ & Fruit item & Percente & Fruit item & Percent $^{\dagger}$ \\
\hline 1 & Orange $^{g}$ & 9.7 & Banana $^{g}$ & 10.9 & Orange $^{g}$ & 13.7 \\
\hline 2 & Bananag & 9.6 & Fried plantain & 8.6 & Bananag & 8.9 \\
\hline 3 & Lemonade & 8.3 & Watermelong & 8.1 & Lemonade & 8.9 \\
\hline 4 & Appleg & 6.9 & Mangog & 7.7 & Natural orange juice ${ }^{g}$ & 8.7 \\
\hline 5 & Natural orange juice ${ }^{g}$ & 6.8 & Lemonade & 7.2 & Appleg & 7.5 \\
\hline 6 & Fried plantain & 6.8 & Appleg & 5.9 & Fried plantain & 5.8 \\
\hline 7 & Watermelong & 4.7 & Boiled plantain & 4.5 & Processed juice brand D & 5.3 \\
\hline 8 & Boiled plantain & 4.6 & Natural orange juice ${ }^{g}$ & 3.2 & Boiled plantain & 4.1 \\
\hline 9 & Processed juice brand D & 4.4 & Lemong & 3.2 & Jelly & 3.1 \\
\hline 10 & Mangog & 4.1 & Bean-stuffed plantain & 3.2 & Watermelong & 2.9 \\
\hline 11 & Lemong & 2.7 & Pineapple drink & 2.7 & Fruit yogurt & 2.9 \\
\hline 12 & Plantain gruel & 2.4 & Processed juice brand D & 2.7 & Blackberry drink & 2.4 \\
\hline 13 & Pineapple drink & 2.4 & Coconut iced popsicle & 2.3 & Processed juice brand $\mathrm{K}$ & 2.4 \\
\hline 14 & Jelly & 2.4 & Blackberry iced popsicle & 2.3 & Lemong & 2.4 \\
\hline 15 & Fruit yogurt & 2.2 & Orangeg & 2.3 & Pineappleg & 2.2 \\
\hline
\end{tabular}

a LSES = low socioeconomic status.

b HSES = high socioeconomic status.

${ }^{c}$ Based on highest number of mentions for each specific fruit item.

d Number of mentions of each specific fruit item as a proportion of 637 total fruit-item mentions for both LSES and HSES schoolchildren.

e Number of mentions of each specific fruit item as a proportion of 221 total fruit-item mentions for LSES schoolchildren.

f Number of mentions of each specific fruit item as a proportion of 416 total fruit-item mentions for HSES schoolchildren.

$g$ Fruit item in its most pure form of consumption (i.e., containing only fruit, without added sugar or other processing)

such as ketchup and packaged soups). It should be noted that $61.5 \%(n=16)$ of the sugar-containing foods (data not shown) were reportedly consumed as beverages (e.g., traditional Guatemalan licuadosblended fruit drinks somewhat analogous to smoothies).

Number/proportion of items. Based on the study results, the HSES group consumed 47 more types of food items than the LSES group (i.e., 237 disaggregated types of food items versus 190, respectively), and 180 items were common to both groups (data not shown). The HSES group reported a total of 88 fruit and vegetable items, or $37.1 \%$ of total food intake, while the LSES group reported a total of 77 fruit and vegetable items, or $40.5 \%$ of total intake. In terms of gender, HSES girls reported consuming 32 vegetable items and 38 fruit items (13.9\% and $16.0 \%$ of total intake, respectively), whereas LSES girls reported consuming 30 vegetable items and 29 fruit items (15.0\% and $10.0 \%$ of total intake). HSES boys reported consuming a total of 32 fruit items and 44 vegetable items (13.5\% and $18.6 \%$ of total intake), while LSES boys reported consuming 25 fruit items and 38 vegetable items $(13.2 \%$ and $20 \%$ of total intake, respectively) (data not shown).

Frequency by item. Table 2 presents the top 15 fruit-containing items reportedly consumed in any form by the study participants (based on the 24-hour dietary intake record), ranked by item and stratified by socioeconomic status (LSES versus HSES). As shown in the table, 10 of the 15 fruit items most frequently mentioned were common to both the LSES and HSES groups (orange, banana, lemonade, apple, natural orange juice, fried plantain, watermelon, boiled plantain, processed juice brand $\mathrm{D}$, and lemon). Banana was the most frequently reported fruit item among LSES children (representing $10.9 \%$ of fruit-item mentions) and the second most frequently reported fruit item among HSES children (representing $8.9 \%$ of fruit-item mentions). On the other hand, orange was the most frequently mentioned fruit item among HSES children (representing $13.7 \%$ of all fruit-item mentions) but the least frequently mentioned fruit item among LSES children (representing 2.3\% of all fruit-item mentions). As indicated in the table, seven of the top 15 fruit items (orange, banana, apple, natural orange juice, watermelon, mango, and lemon) were consumed in their purest form (whole or juiced, with no added sugar or other processing), with six of the seven items (all except mango) common to both socioeconomic groups.

Table 3 presents the same information for vegetables. As shown in the table, 12 of the overall top 15 vegetable-containing items (ketchup, chicken and vegeta- bles stew, pasta and tomato sauce, fried potatoes, boiled potatoes, recado, tomato, chirmol, beef and vegetables stew, lettuce, cucumber, and radish) were common to both the LSES and HSES groups. Only seven of the top 15 items reported overall (tomato, chirmol, lettuce, cucumber, onion, cooked carrot, and radish) were "vegetables" in pure form (i.e., containing only vegetable ingredients and eaten raw, whole, chopped, or cooked, without added oil), with the remainder corresponding to composite foods or recipes containing vegetables. Five of these seven items were common to both socioeconomic groups.

Frequency by study participant. Table 4 shows the number and percentage of study participants who reported consuming fruit or vegetable items during the 24-hour evaluation period, by socioeconomic status and gender; $414(92.2 \%)$ reportedly consumed at least one fruit or vegetable, or a food item containing components from one or both food groups. Among LSES boys, there were almost three times more "non-consumers" compared to their HSES counterparts $(17.0 \%$ versus $3.6 \%$, respectively). Similarly, three times as many LSES girls were categorized as "non-consumers" compared to HSES girls (8.8\% versus $2.5 \%$ ).

The mean/median values for overall fruit/vegetable intake in grams during 
TABLE 3. Top 15 vegetable items most frequently mentioned in 24-hour dietary intake recall by third- and fourth-grade schoolchildren in Quetzaltenango, Guatemala (April-June 2005)

\begin{tabular}{|c|c|c|c|c|c|c|}
\hline \multirow[b]{2}{*}{ Rank $^{c}$} & \multicolumn{2}{|l|}{$\begin{array}{c}\text { Overall } \\
(n=449)\end{array}$} & \multicolumn{2}{|l|}{$\begin{array}{l}\text { LSESa }^{\text {LS }}(n=219)\end{array}$} & \multicolumn{2}{|l|}{$\begin{array}{l}\text { HSES }^{b} \\
(n=230)\end{array}$} \\
\hline & Vegetable item & Percent $^{d}$ & Vegetable item & Percent ${ }^{\mathrm{e}}$ & Vegetable item & Percent $^{f}$ \\
\hline 1 & Ketchup & 10.8 & Recadog & 9.4 & Ketchup & 13.5 \\
\hline 2 & Chicken and vegetables stew & 7.4 & Chicken and vegetables stew & 9.4 & Tomato ${ }^{\mathrm{h}}$ & 7.4 \\
\hline 3 & Pasta and tomato sauce & 7.4 & Pasta and tomato sauce & 8.7 & Fried potatoes & 7.1 \\
\hline 4 & Fried potatoes & 7.1 & Ketchup & 7.4 & Pasta and tomato sauce & 6.4 \\
\hline 5 & Boiled potatoes & 6.1 & Fried potatoes & 7.1 & Lettuce $^{\text {h }}$ & 6.1 \\
\hline 6 & Recado & 5.8 & Beef and vegetables stew & 7.1 & Boiled potatoes & 5.9 \\
\hline 7 & Tomato $^{\text {h }}$ & 5.8 & Boiled potatoes & 6.5 & Chirmol $^{\mathrm{h}}$ & 5.9 \\
\hline 8 & Chirmol $^{\mathrm{h}}$ & 5.7 & Chirmol $^{\mathrm{h}}$ & 5.5 & Chicken and vegetables stew & 5.9 \\
\hline 9 & Beef and vegetables stew & 5.3 & Tomato $^{\text {h }}$ & 3.9 & Onion ${ }^{\mathrm{h}}$ & 3.8 \\
\hline 10 & Lettuce $^{\text {h }}$ & 4.6 & Cucumber $^{\mathrm{h}}$ & 3.6 & Beef and vegetables stew & 3.8 \\
\hline 11 & Cucumber h & 3.4 & Cooked carroth & 3.2 & Cucumber ${ }^{\mathrm{h}}$ & 3.3 \\
\hline 12 & Onion $^{h}$ & 2.4 & Potato dough tamale & 3.2 & Recado & 3.1 \\
\hline 13 & Guacamole & 2.0 & Lettuce $^{h}$ & 2.6 & Guacamole & 2.8 \\
\hline 14 & Cooked carrot ${ }^{\mathrm{h}}$ & 2.0 & Radish ${ }^{\mathrm{h}}$ & 1.9 & Raw carrot ${ }^{\text {h }}$ & 2.3 \\
\hline 15 & Radish ${ }^{\mathrm{h}}$ & 1.9 & Chayote $^{h}$ & 1.9 & Radish $^{\mathrm{h}}$ & 1.8 \\
\hline
\end{tabular}

a LSES = low socioeconomic status.

b HSES = high socioeconomic status.

c Based on highest number of mentions for each specific fruit item.

d Number of mentions of each specific vegetable item as a proportion of 701 total vegetable-item mentions for both LSES and HSES schoolchildren.

e Number of mentions of each specific vegetable item as a proportion of 309 total vegetable-item mentions for LSES schoolchildren.

f Number of mentions of each specific food item as a proportion of 392 total vegetable-item mentions for HSES schoolchildren.

$\mathrm{g}$ The use of italics indicates traditional food recipes in form of consumption most common within local culture (e.g., recado, a tomato-based sauce; chirmol, a raw tomato sauce added as a condiment; and guacamole, an avocado paste).

h Vegetable item in its most pure form of consumption (i.e., containing only vegetables and eaten raw, whole, chopped, or cooked, without added oil).

TABLE 4. Number and proportion of fruit/vegetable consumers and non-consumers among thirdand fourth-grade schoolchildren in Quetzaltenango, Guatemala, by socioeconomic status and gender (April-June 2005) ${ }^{\mathrm{a}}$

\begin{tabular}{|c|c|c|c|c|c|c|c|c|}
\hline & \multicolumn{4}{|c|}{$\begin{array}{c}\text { LSES }^{b} \\
(n=219)\end{array}$} & \multicolumn{4}{|c|}{$\begin{array}{c}\text { HSES }^{c} \\
(n=230)\end{array}$} \\
\hline & No. & $\begin{array}{c}\text { Overall } \\
\%\end{array}$ & $\begin{array}{c}\text { Girls } \\
\%\end{array}$ & $\begin{array}{c}\text { Boys } \\
\%\end{array}$ & No. & $\begin{array}{c}\text { Overall } \\
\%\end{array}$ & $\begin{array}{c}\text { Girls } \\
\%\end{array}$ & $\begin{array}{c}\text { Boys } \\
\%\end{array}$ \\
\hline \multicolumn{9}{|l|}{ Consumers } \\
\hline Fruit & 127 & 58.0 & 65.5 & 50.0 & 175 & 76.1 & 79.0 & 73.0 \\
\hline Vegetables & 166 & 75.8 & 80.5 & 70.8 & 194 & 84.3 & 83.2 & 85.6 \\
\hline Fruit or vegetables & 191 & 87.2 & 91.2 & 83.0 & 223 & 97.0 & 97.5 & 96.4 \\
\hline \multicolumn{9}{|l|}{ Non-consumers } \\
\hline No fruit or vegetables & 28 & 12.8 & 8.8 & 17.0 & 7 & 3.0 & 2.5 & 3.6 \\
\hline
\end{tabular}

a Consumers of fruit and vegetables were defined as study participants reporting consumption of any fruit or vegetable item during a 24 -hour evaluation period, and were mutually excluded.

b LSES = low socioeconomic status.

${ }^{c}$ HSES $=$ high socioeconomic status.

the 24-hour evaluation period are presented in Table 5 by socioeconomic status. Statistically significant differences were found between socioeconomic classes. The HSES study participants had a statistically significant higher mean intake of combined fruit/vegetable items and more grams of fruit intake than LSES children. In terms of mean vegetable intake, results for the two groups differed, but not in a statistically significant manner.

Adequacy. Table 6 shows the proportion of children with adequate fruit/ vegetable intake (i.e., intake values greater than $400 \mathrm{~g}$ per day) by socioeconomic status and gender. Overall, more than half of the population $(56.3 \%)$ had inadequate intake. When stratified by socioeconomic and gender, LSES boys had the highest proportion of inadequate intake, with more than $70 \%$ of this subgroup reporting less than $400 \mathrm{~g}$ of combined fruit/vegetable intake.

Estimated energy contribution. As shown in Table 7, the total daily energy contribution from all fruit and vegetable items reportedly consumed amounts to about one-fifth of the average 24-hour energy intake. Among HSES children, the total fruit/vegetable contribution to energy is equivalent between boys and girls. In contrast, LSES girls reported a 7-percentage point greater fruit/vegetable contribution to their energy intake compared to LSES boys. In addition, the HSES sample indicated balanced (50:50) portions of energy contributed by fruit and vegetable items, whereas in the LSES sample fruit items accounted for about one-third of the total fruit/vegetable energy contribution. In terms of the combined fruit/vegetable energy contribution (for both the LSES and HSES groups), the distribution was skewed, with a mean of 409 kcal of energy provided and a median of $347 \mathrm{kcal}$. Total energy for 24-hour food intake ranged from a minimum of $544 \mathrm{kcal}$ to a maximum of $4302 \mathrm{kcal}$ (data not shown). The median was $1869 \mathrm{kcal}$, and the distribution of values for the 449 respondents closely approximated a normal (Gaussian) distribution. Thus, based on this study's standard definitions of fruit and vegetables (i.e., those based on local use/perceptions of fruits and vegetables versus the WCRF / AICR classifications), the combined mean and median fruit/ vegetable contributions to total energy intake (for both the LSES and HSES 
TABLE 5. Grams of fruit/vegetable intake among third- and fourth-grade fruit and vegetable consumers in Quetzaltenango, Guatemala, by socioeconomic status (April-June 2005),

\begin{tabular}{|c|c|c|c|c|c|c|c|}
\hline & \multicolumn{2}{|c|}{$\begin{array}{c}\text { Overall } \\
(n=414)\end{array}$} & \multicolumn{2}{|c|}{$\begin{array}{c}\text { LSESC }^{2} \\
(n=191)\end{array}$} & \multicolumn{2}{|c|}{$\begin{array}{c}\text { HSES }^{d} \\
(n=223)\end{array}$} & \multirow[b]{2}{*}{$P$-value ${ }^{f}$} \\
\hline & $\underset{\text { SD }^{\mathrm{e}}}{\operatorname{Mean} \pm}$ & $\begin{array}{c}\text { Median } \\
(\min .-\max .)\end{array}$ & $\begin{array}{l}\text { Mean } \\
\pm S D\end{array}$ & $\begin{array}{c}\text { Median } \\
(\min .-\max .)\end{array}$ & $\begin{array}{l}\text { Mean } \\
\pm S D\end{array}$ & $\begin{array}{c}\text { Median } \\
(\min .-\max .)\end{array}$ & \\
\hline Fruit & $\begin{array}{l}353.4 \pm \\
288.1\end{array}$ & $\begin{array}{c}250 \\
(5-1724)\end{array}$ & $\begin{array}{l}262.5 \pm \\
205.5\end{array}$ & $\begin{array}{c}240.0 \\
(5-1184)\end{array}$ & $\begin{array}{l}419.4 \pm \\
320.2\end{array}$ & $\begin{array}{c}328.0 \\
(10-1724)\end{array}$ & $<0.001$ \\
\hline Vegetables & $\begin{array}{l}234.0 \pm \\
165.6\end{array}$ & $\begin{array}{c}240 \\
(5-1044)\end{array}$ & $\begin{array}{l}263.6 \pm \\
184.3\end{array}$ & $\begin{array}{c}240.0 \\
(5-1044)\end{array}$ & $\begin{array}{l}208.7 \pm \\
143.4\end{array}$ & $\begin{array}{c}199.5 \\
(0-820)\end{array}$ & 0.018 \\
\hline vegetables) & $\begin{array}{l}461.3 \pm \\
332.5\end{array}$ & $\begin{array}{c}375.5 \\
(5-2138)\end{array}$ & $\begin{array}{l}403.7 \pm \\
278.7\end{array}$ & $\begin{array}{c}321.0 \\
(5-1366)\end{array}$ & $\begin{array}{l}510.7 \pm \\
365.9\end{array}$ & $\begin{array}{c}413.0 \\
(5-2138)\end{array}$ & 0.036 \\
\hline
\end{tabular}

\footnotetext{
a Consumers of fruit and vegetables were defined as study participants reporting consumption of any fruit or vegetable item during a 24-hour evaluation period.

b Includes non-fruit and non-vegetable components of composite foods (e.g., sugar or fat used in food preparation or processing).

c LSES = low socioeconomic status.

d HSES = high socioeconomic status.

e $\mathrm{SD}=$ standard deviation.

f $P$-values are based on log-transformed fruit/vegetable intake values using a general linear model, controlling for gender.
}

TABLE 6. Proportion of third- and fourth-grade schoolchildren in Quetzaltenango, Guatemala, reporting fruit/vegetable intake over a 24-hour evaluation period below or above the $\mathrm{WHO}^{\mathrm{a}} 400 \mathrm{~g}$ recommended daily level, by socioeconomic status and gender (April-June 2005)

\begin{tabular}{lcccccc}
\hline & Overall & & \multicolumn{2}{c}{ HSES $^{c}$} \\
\cline { 2 - 4 } & $\begin{array}{c}(n=449) \\
\%\end{array}$ & $\begin{array}{c}\text { Girls } \\
(n=113) \\
\%\end{array}$ & $\begin{array}{c}\text { Boys } \\
(n=106) \\
\%\end{array}$ & & $\begin{array}{c}\text { Girls } \\
(n=119) \\
\%\end{array}$ & $\begin{array}{c}\text { Boys } \\
(n=111) \\
\%\end{array}$ \\
\hline$<400$ g/day & 56.3 & 57.5 & 70.8 & 49.6 & 48.6 \\
$\geq 400$ g/day & 43.7 & 42.5 & 29.2 & 50.4 & 51.4 \\
\hline
\end{tabular}

a World Health Organization.

b LSES = low socioeconomic status.

c HSES $=$ high socioeconomic status .

TABLE 7. Proportion of energy contribution from fruits and vegetables among third- and fourthgrade schoolchildren in Quetzaltenango, Guatemala, based on 24-hour dietary intake, by socioeconomic status and gender (April-June 2005)

\begin{tabular}{|c|c|c|c|c|c|c|}
\hline & \multicolumn{3}{|c|}{ LSES $^{c}$} & \multicolumn{3}{|c|}{ HSES $^{d}$} \\
\hline & $\begin{array}{c}\text { Total } \\
(n=219)\end{array}$ & $\begin{array}{c}\text { Girls } \\
(n=113)\end{array}$ & $\begin{array}{c}\text { Boys } \\
(n=106)\end{array}$ & $\begin{array}{c}\text { Total } \\
(n=230)\end{array}$ & $\begin{array}{c}\text { Girls } \\
(n=119)\end{array}$ & $\begin{array}{c}\text { Boys } \\
(n=111)\end{array}$ \\
\hline Fruits & $\begin{array}{c}6.5 \pm 8.8 \\
(2.2)\end{array}$ & $\begin{array}{c}7.4 \pm 9.2 \\
(3.7)\end{array}$ & $\begin{array}{c}5.6 \pm 8.3 \\
(10.1)\end{array}$ & $\begin{array}{c}10.8 \pm 10.8 \\
(8.2)\end{array}$ & $\begin{array}{c}11.7 \pm 11.2 \\
(10.4)\end{array}$ & $\begin{array}{c}9.9 \pm 10.3 \\
(6.8)\end{array}$ \\
\hline Vegetables & $\begin{array}{c}12.6 \pm 13.1 \\
(8.6)\end{array}$ & $\begin{array}{c}14.1 \pm 13.8 \\
(11.6)\end{array}$ & $\begin{array}{c}10.9 \pm 12.1 \\
(15.7)\end{array}$ & $\begin{array}{c}10.4 \pm 11.0 \\
(6.7)\end{array}$ & $\begin{array}{c}9.8 \pm 11.2 \\
(6.1)\end{array}$ & $\begin{array}{c}11.0 \pm 10.7 \\
(8.4)\end{array}$ \\
\hline $\begin{array}{l}\text { Fruit and/or } \\
\text { vegetables }\end{array}$ & $\begin{array}{c}19.1 \pm 14.9 \\
\quad(17.4)\end{array}$ & $\begin{array}{c}21.5 \pm 14.9 \\
(20.8)\end{array}$ & $\begin{array}{c}16.5 \pm 14.5 \\
(14.0)\end{array}$ & $\begin{array}{c}21.2 \pm 14.6 \\
\quad(18.8)\end{array}$ & $\begin{array}{c}21.5 \pm 15.8 \\
(18.6)\end{array}$ & $\begin{array}{c}20.8 \pm 13.3 \\
(19.1)\end{array}$ \\
\hline
\end{tabular}

a Values = mean \pm standard deviation (median).

b Includes non-fruit and non-vegetable components of composite foods (e.g., sugar or fat used in food preparation or processing)

c LSES = low socioeconomic status.

d HSES = high socioeconomic status

groups) amounted to 21.9 and $18.6 \%$, respectively.

After making the reclassification exclusions of potatoes, plantains, and bananas, in accordance with the WCRF/ AICR convention (6), the total estimated combined fruit/vegetable energy contribution to LSES study participants $(n=219)$ was $11.8 \%$ (SD, $11.3 \%)$. Among HSES study participants $(n=230)$, fruit/ vegetable intake accounted for $14.2 \%$ of the total energy intake (SD, $12.1 \%$ ) (data not shown). The respective medians for the two social classes were $9.1 \%$ and $12.2 \%$, respectively. Again, based on the adjusted percentages, girls from both socioeconomic classes had a higher proportion of energy contributed from fruit and vegetables compared to boys, but these differences were not statistically significant.

\section{DISCUSSION}

The disparity of the study results is important, as it illustrates the difference between a gram-based and energy density-based approach to analysis of fruit/vegetable intake. Using the first approach, results indicate that more than half of all public and private schoolchildren in the city of Quetzaltenango have inadequate fruit/vegetable intake, based on the WHO criterion of $400 \mathrm{~g}$ of daily intake (7). In contrast, using the second approach, results indicate the median contribution of fruit/vegetable items to study participants' daily energy was $11.3 \%$, exceeding the proportion of $7 \%$ of total energy recommended by the WCRF (6) for fruit/vegetable intake. As indicated in diverse studies, Quetzaltenango children would not be the exception in having overall fruit/vegetable consumption values below internationally recommended standards (in terms of grams). For example, the "Pro Children" crosssectional survey described by Yngve et al. (26) describes cases of insufficient fruit/vegetable intake in nine European countries, and the study by Perry et al. (11) highlights the low fruit/vegetable intake of children in the United States. When quantified by socioeconomic group, the results for HSES and LSES schoolchildren in this study indicating fruit/vegetable intake below the recommended level are similar to those reported by Olivares et al. $(21,27)$, who reported median intake as low as $200 \mathrm{~g}$ among female schoolchildren from various socioeconomic strata in Chile.

\section{Limitations}

Agudo (24) describes key methodological issues that have emerged in the study of fruit/vegetable intake, including those related to the definitions of terms. These issues were experienced in the present study in efforts to define individual fruits and vegetables in a way that conformed as much as possible to global recommenda- 
tions yet matched local (Guatemalan) perceptions. It was ultimately decided that, in this study, enumeration and classification of fruits and vegetable items should be based on definitions drawn from the Guatemalan context. This was justified based on the assumption that applying definitions of individual fruits and vegetables as they are commonly understood in Guatemala would facilitate the development and implementation of any future public awareness campaigns based on the study results (i.e., it was assumed that the target audience would better absorb public health messages about fruit and vegetables based on prevailing cultural definitions). Therefore, this study defined fruits and vegetables as they are understood locally. However, the study's assessment of the combined fruit/vegetable contribution to total 24-hour energy intake (described below) was based on global recommendations and definitions.

A second important methodological issue is the handling of composite or mixed foods, as pointed out by $\mathrm{O}^{\prime}$ Brien et al. (28). Due to the limitations of existing food composition tables, this study did not analyze the fruit or vegetable components of these foods separately. Therefore, the estimates of fruit/vegetable intake presented in this article (in terms of both grams and energy) include the non-fruit and non-vegetable components of composite foods (sugar or fat used in food preparation or processing, for example, both of which would affect total energy contribution and total weight of the food item). It should be noted, however, that despite the inclusion of the additional weight contributed by non-fruit and non-vegetable components of composite foods, more than half $(56.3 \%)$ of the study participants were still below the WHO recommended daily intake level. Although fruit and vegetables are emphasized in the traditional Guatemalan diet, the findings of this study indicate the need for greater fruit/ vegetable intake, based on the WHO recommendations. This may call for more attention to how fruit and vegetables are consumed. For example, study participants reportedly consumed most fruit items in the form of beverages, whereas vegetables were often eaten along with other foods in mixed dishes. Although fruit and vegetables are naturally low in energy, when they are consumed as part of composite foods or recipes, as is usually the case in Quetzaltenango cuisine, they frequently have added sugar or other sweeteners $(n=42)$ and fat $(n=37)$, or both, thus increasing the energy density as well as the potential health risks.

The cross-sectional nature of the study and its use of a single 24-hour evaluation period are also a limitation in terms of the future applicability of its methodology. The lack of multiple evaluation periods and actual observation of food intake precludes validating the data collection instrument (the 24-hour recall recording booklet) for studies of the entire school-aged population in Quetzaltenango. This methodology is therefore best suited for analysis of food intake among age groups similar to those covered in the study. Furthermore, like other studies based on a single 24-hour dietary intake record, these results cannot take into account individual variation in intake throughout the week (29) or with seasonality (30). However, because this method generates data on the food intake of children from both high and low socioeconomic settings (collected simultaneously), and thus reflects group differences, it is appropriate for group-level comparisons.

Another limitation of the study is related to the cognitive ability of children. The dietary intake recall methods used in this study are limited by children's capacity to remember details and estimate quantities $(31,32)$; foods are often left out of diet records when children forget to draw part of a meal, or a snack. Others have identified these difficulties and have suggested alternatives, such as including direct observation, or interviewing parents (33). Direct observation would have been impractical in this study, as children could not be observed at home, and interviewing the parents would have excluded key information about foods consumed by the children at school, with friends, or at home without the parents' knowledge. However, use of the CeSSIAM pictorial approach (an adaptation of the "write and draw" technique used to assess food intake in school-age children (33-35), in which children draw what they eat while or soon after their meals) complemented by the face-to-face interview partially addressed the issue of children's limited recall. In addition, to mitigate the potential for misclassification of the food items depicted in the children's drawings, the interviewing of the children included interactions with a trained dietician, who ascertained exactly what food items were depicted in the children's drawings, probed for details about foods names and quantities, and procured additional information about food or beverages that may have been inadvertently omitted from the child's description of his/her 24-hour food intake. When children were unsure of amounts, normal-size portions were assumed, based on common household measures and utensils.

As mentioned above, the study sample was not designed to represent all schoolchildren from Quetzaltenango but rather to capture extremes in high and low socioeconomic status based on school type. The effect of socioeconomic status thus represents another limitation of this study. For example, schoolchildren from either the HSES or the LSES group could have received more parental help at home in completing the pictorial exercise compared to those in the other group, which could have differentially affected the quality of the data. Therefore, these research results should not be generalized for schools other than those that participated in the study, whose principal focus in terms of comparisons and the presentation of results was the contrast between HSES and LSES children. For example, this study indicates HSES children consume more fruit and vegetables compared to LSES children, and that LSES children have a lower prevalence of meeting the recommended $400 \mathrm{~g}$ of daily fruit/vegetable intake. However, these results are not generalizable to middleincome children, because middle-income schools were not included in the study.

\section{Recommendations}

Although this study focused on the differences between two socioeconomic groups (HSES and LSES), it also found that among the study population boys were less likely to consume fruit and vegetables compared to girls. These results concur with other studies conducted in the United States, Europe, and the United Kingdom that show more boys than girls consume a diet lacking in fruit and vegetables $(9,14,26)$. This relationship was strongest in boys from the LSES group, which had the highest percentage of "non-fruit or vegetable consumers" and those not meeting the recommended fruit/vegetable intake. LSES children, particularly boys, should therefore be specifically targeted for public 
health interventions to increase their fruit/vegetable consumption. Increasing fruit/vegetable intake among this group will be challenging, however, given the likely economic constraints. Further research is needed to identify potential means of increasing the availability and accessibility of fruit and vegetables to LSES children.

The evaluation exercise undertaken in this study highlights the need for consideration of an overriding issue in epidemiological research on fruit/vegetable intake-namely, as raised by $\mathrm{O}^{\prime}$ Brien et al. (28), what constitutes a fruit or vegetable serving in the "real world" (in which both food groups are often combined with foods from other groups in recipes but are not disaggregated at the level of food composition table values). This issue is particularly relevant in Guatemala, where fruit and vegetables are normally consumed in mixed dishes and fruit drinks, as described above. Several field researchers have addressed the issue of composite foods, including $\mathrm{O}^{\prime}$ Brien et al. (28), who raised the important role of composite foods in fruit/vegetable intake. Although their analysis was conducted among an adult population, it revealed two important issues also experienced in the current study: the overestimation of intake that results from the inclusion of composite foods, and the variation in meeting WHO recommendations by socioeconomic class. In the same article (28), composite foods are recognized as an important source of vegetables, but not of fruits-an observation that was also made in the current study. As mentioned above, the results of the current study show that fruit/vegetable intake among the study sample are inadequate in terms of not only gram-based standards but also in their representative proportion of mixed recipes and preparations with added sugar or fats. These findings have clear and specific implications for both nutritional guidance and evaluation of compliance with recommended levels of consumption, and more research is needed to address this issue.

Another recommendation is the need for localization of food group definitions. For example, WCRF/AICR experts (6) found that diets higher in fruits, vegetables, or both offer significant protection against cancer, and subsequently recommended guidelines for determining a population's level of compliance with cancer-prevention practices, which advocate that $7 \%$ or more of total daily energy be derived from fruit and vegetables. In defining the "fruit" and "vegetable" categories, however, they excluded the Musa genus (i.e., bananas and plantains, generally considered fruit in the Guatemalan culture) and the potato, respectively, classifying them as starches instead, based on the supposition that both foods had positive, cancer-protective effects due to mechanisms similar to those of other starchy foods (6). In addition, they laid out the following specification: "Energy values are for vegetables and fruits either raw, or prepared or cooked and ready to eat, or reconstituted with the addition of water if initially dried, but without any added fat or sugar" (6: 512-513). The results of this analysis indicate the WCRF/ AICR definitions are at variance with Guatemalan cultural perceptions of fruit and vegetables and underscore the need for more specific (localized) recommendations for national fruit/vegetable consumption. On the other hand, public health messages designed to increase fruit/vegetable intake in Guatemala may need to promote the consumption of commonly consumed fruit and vegetables whose local definitions and classifications match those of the WCRF/AICR. For example, increased intake of oranges, watermelons, tomatoes, lettuce, cucumbers, and cooked carrots could be specifically encouraged, as these food items fit the WCRF/AICR criteria and, according to the current study, are commonly consumed in Guatemalan cuisine, even among LSES groups.

According to Nishida et al. (36), a public health goal is considered successfully achieved when the mean of a population's distribution equals or exceeds the desired percentage of participation. Based on the current results for total fruit/vegetable intake as a proportion of total energy intake, both socioeconomic groups analyzed in this study (LSES and HSES) appear to have met the WCRF cancer-prevention goal of $7 \%$. Given the skewed results for both populations, however, use of the median energy contribution levels may be more representative of the true proportions. In addition, the results of this study-though they may differ from those generated by the pristine, disaggregated analyses advocated by the WCRF/AICR expert panel-prove that it is virtually impossible to separate "pure" fruit/vegetable content from fruit/vegetable compo- nents of composite or mixed dishes when calculating total fruit/vegetable intake.

It should also be noted that a general public awareness message promoting increased fruit/vegetable consumption in Guatemala may inadvertently increase fat and sugar intake, as most fruits and vegetables are prepared with added sugar or consumed in mixed dishes that include other, more energy-dense components. The frequent reporting by study participants of fruits and vegetables consumed as mixed dishes provides a good example of the gap between theory and practice (how fruit and vegetables are $a c$ tually eaten versus perceptions of how they are eaten), underscored by official recommendations for fruit/vegetable intake such as those from the WCRF. For example, of the 30 fruits and vegetables reportedly consumed among LSES children, only the following 10 meet WCRF recommendations: watermelons; apples; mangos; oranges; radishes; cucumbers; cooked carrots; tomatoes (plain, and in the form of raw tomato sauce known as chirmol); lettuce; and chayote (an edible plant of the gourd family that is cooked or eaten raw in salads). Consumption of these 10 fruit and vegetables, which are consumed in forms with no (or minimal) added sugar or oil, could be encouraged in public health messages to promote increased, healthy fruit/vegetable intake. On the other hand, foods such as recado (a tomato-based sauce) and stews, which are part of the traditional food pattern but entail the combination of vegetables with more energy-dense foods, would not meet WCRF recommendations. Presumably, the foods most frequently mentioned in this study among LSES children are affordable and thus available to children of all socioeconomic classes.

In the course of conducting this study, two promising types of interventions were identified. The first is the introduction of fruits as alternative snacks by school kiosks. LSES children, who have limited economic resources, would benefit more from the addition of a fruit or vegetable to the subsidized National School Feeding Program (refacción escolar) than from programs targeting greater fruit and vegetable intake in the home. (The menu for this program currently consists of atol-gruel made from any available cereal-and bread or corn tamalito.) However, further studies would be needed to determine if these foods would be culturally acceptable as 
part of the school diet and if they present any health risks related to hygiene or food preparation practices prior to their promotion as part of a campaign to improve health through increased fruit/ vegetable consumption.

Acknowledgements. The authors thank the Quetzaltenango local education authorities for authorizing this study, and the personnel of the participating schools for their approval, patience, and active collaboration; Dr. Oscar Hernandez, Coordinator of the Health Sciences School at Rafael Landívar University in Quetzaltenango, for his collaboration; nutrition students Ericka Lopez and Yerly Gramajo, for assisting with data collection, and Vilma Calderon, Anabella Peralta, Aura Schell, Lilian Hernandez, Marcel Sac, and Paula Gonzalez, for helping with recruitment and the dis- tribution of consent forms; Dr. Jacob Seidell of the Department of Health Sciences at Vrije University in Amsterdam for his collaborative partnership with CeSSIAM; Dr. Marieke Vossenaar of CeSSIAM for her assistance on data analysis; the parents of the study participants for authorizing their children's participation; and the children themselves for their enthusiastic contributions to the study.

\section{REFERENCES}

1. Hu FB. Plant-based foods and prevention of cardiovascular disease: an overview. Am J Clin Nutr. 2003;78(Suppl 3):S544-51.

2. Bazzano LA, Serdula MK, Liu S. Dietary intake of fruits and vegetables and risk of cardiovascular disease. Curr Atheroscler Rep. 2003;5(6):492-9.

3. Bes-Rastrollo M, Martinez-González MA, Sanchez-Villegas A, de la Fuente-Arrilaga C, Martinez JA. Association of fiber intake and fruit/vegetable consumption with weight gain in a Mediterranean population. Nutrition. 2006;22(5):504-11.

4. Spiegel SA, Foulk D. Reducing overweight through a multidisciplinary school-based intervention. Obesity (Silver Spring). 2006;14(1): 88-96.

5. Steinmetz KA, Potter JD. Vegetables, fruit, and cancer prevention: a review. J Am Diet Assoc. 1996;96(10):1027-39.

6. World Cancer Research Fund; American Institute for Cancer Research. Food, nutrition and the prevention of cancer: a global perspective. Washington: AICR; 1997. p. 512.

7. World Health Organization. Fruit and vegetable promotion initiative. Geneva: WHO; 2003.

8. Baxter IA, Schröder MJ, Bower JA. Children's perceptions of and preferences for vegetables in the West of Scotland: the role of demographic factors. J Sens Stud. 2000;15(4):361-81.

9. Reynolds KD, Baranowski T, Bishop DB, Farris RP, Binkley D, Nicklas TA, et al. Patterns in child and adolescent consumption of fruit and vegetables: effects of gender and ethnicity across four sites. J Am Coll Nutr. 1999;18(3): 248-54.

10. Anderson JV, Bybee DI, Brown RM, McLean DF, Garcia EM, Breer ML, et al. 5 a day fruit and vegetable intervention improves consumption in a low income population. J Am Diet Assoc. 2001;101(2):195-202.

11. Perry CL, Bishop DB, Taylor G, Murray DM, Mays RW, Dudovitz BS, et al. Changing fruit and vegetable consumption among children: the 5-a-Day Power Plus program in St. Paul Minnesota. Am J Public Health. 1998;88(4): 603-9.

12. Klepp KI, Pérez-Rodrigo C, De Bourdeaudhuij I, Due PP, Elmadfa I, Haraldsdóttir J, et al. Promoting fruit and vegetable consumption among European schoolchildren: rationale, conceptualization and design of the Pro Children Project. Ann Nutr Metab. 2005;49(4):212-20.

13. Wind M, De Bourdeaudhuij I. A qualitative exploration of determinants of fruit and vegetable intake among 10- and 11-year-old schoolchildren in the Low Countries. Ann Nutr Metab. 2005;49(4):228-35.

14. Glynn L, Emmett P, Rogers I. Food and nutrient intakes of a population sample of 7-yearold children in the south-west of England in 1999/2000-what difference does gender make? J Hum Nutr Diet. 2005;18(1):7-19.

15. Wind M, De Bourdeaudhuij I, te Velde SJ, Sandvik C, Due P, Klepp KI, et al. Correlates of fruit and vegetable consumption among 11year-old Belgian-Flemish and Dutch schoolchildren. J Nutr Educ Behav. 2006; 38(4):211-21.

16. Batrouni L, Navarro A, Sabulsky J, Fanto S, Rodriguez A. [Situación alimentaria de escolares en relación con su condición social: Córdoba, República Argentina]. Arch Latinoam Nutr. 1993;43(1):12-9.

17. Hampl JS, Taylor CA, Johnston CS. Intakes of vitamin $C$, vegetables and fruits: which schoolchildren are at risk? J Am Coll Nutr. 1999;18(6):582-90.

18. Giskes K, Turrell G, Patterson C, Newman B. Socio-economic differences in fruit and vegetable consumption among Australian adolescents and adults. Public Health Nutr. 2002; 5(5):663-9.

19. Shahar D, Shai I, Vardi H, Shahar A, Fraser D. Diet and eating habits in high and low socioeconomic groups. Nutrition. 2005;21(5):559-66.

20. Temple NJ, Steyn NP, Myburgh NG, Nel JH. Food items consumed by students attending schools in different socioeconomic areas in Cape Town, South Africa. Nutrition. 2006; 22(3):252-8

21. Olivares CS, Bustos ZN, Lera ML, Zelada ME. Estado nutricional, consumo de alimentos y actividad física en escolares mujeres de diferente nivel socioeconómico de Santiago, Chile. Rev Med Chil. 2007;135(1):71-8.

22. Flores M, Menchú MT, Arroyave G. Ingesta de micronutrientes en las áreas rurales de Centro América y Panamá. Arch Latinoam Nutr. 1969;19(3):265-78.

23. Solomons N. Plant-based diets are traditional in developing countries: 21st century challenges for better nutrition and health. Asia Pac J Clin Nutr. 2000;9 Suppl:S41-54.

24. Agudo A. Measuring intake of fruit and vegetables. Presentation 3.4. Joint FAO/WHO Workshop on Fruit and Vegetables for Health, 1-3 September 2004, Kobe, Japan. Available from: www.who.int/dietphysicalactivity/ publications/fruit_vegetables_report.pdf.

25. Menchú MT, Méndez H, Barrera MA, Ortega L. Valor nutritivo de los alimentos de Centroamérica. Guatemala City: Instituto de Nutri- ción de Centro América y Panamá, Pan American Health Organization; 2000.

26. Yngve A, Wolf A, Poortvliet E, Elmadfa I, Brug J, Ehrenblad B, et al. Fruit and vegetable intake in a sample of 11-year-old children in 9 European countries: the Pro Children Crosssectional Survey. Ann Nutr Metab. 2005;49(4): 236-45.

27. Olivares S, Kain J, Lera L, Pizarro F, Vio F, Moran C. Nutritional status, food consumption and physical activity among Chilean school children: a descriptive study. Eur J Clin Nutr. 2004;58(9):1278-85.

28. O'Brien MM, Kiely M, Galvin M, Flynn A The importance of composite foods for estimates of vegetable and fruit intakes. Pub Health Nutr. 2003;6(7):711-26

29. Lytle LA, Nichaman MZ, Obarzanek E, Glovski E, Montgomery D, Nicklas T, et al. Validation of 24-hour recalls assisted by food records in third-grade children. The CATCH Collaborative Group. J Am Diet Assoc. 1993; 93(12):1431-6.

30. Willet WC. Nutritional epidemiology. 2nd ed. New York: Oxford University Press; 1998.

31. Baxter SD, Smith AF, Litaker MS, Guinn $\mathrm{CH}$, Shaffer NM, Baglio ML, et al. Recency affects reporting accuracy of children's dietary recalls. Ann Epidemiol. 2004;14(6):385-90.

32. Moore GF, Tapper K, Murphy S, Clark R, Lynch R, Moore L. Validation of a selfcompletion measure of breakfast foods, snacks and fruits and vegetables consumed by 9- to 11-year-old schoolchildren. Eur J Clin Nutr. 2007;61(3):420-30.

33. Livingstone MB, Robson PJ. Measurement of dietary intake in children. Proc Nutr Soc. 2000;59(2):279-93.

34. Pridmore P, Bendelow G. Images of health: exploring beliefs of children using the 'drawand-write' technique. Health Educ J. 1995;54 (4):473-88

35. Edmunds LD, Ziebland S. Development and validation of the Day in the Life Questionnaire (DILQ) as a measure of fruit and vegetable questionnaire for 7-9 year olds. Health Educ Res. 2002;17(2):211-20.

36. Nishida C, Uauy R, Kumanyika S, Shetty P. The Joint WHO/FAO expert consultation on diet, nutrition and the prevention of chronic diseases: process, product and policy implications. Public Health Nutr. 2004;7(1A):245-50.

Manuscript received on 3 October 2007. Revised version accepted for publication on 20 July 2008. 
RESUMEN Objetivo. Determinar si el consumo de frutas y vegetales en escolares de ingresos altos y bajos de zonas urbanas de Quetzaltenango es el adecuado según las recomendaciones de la Organización Mundial de la Salud (OMS).

Consumo de frutas y vegetales en escolares de Quetzaltenango, Guatemala

Palabras clave
Métodos. Estudio transversal en 449 niñas y niños de tercer y cuarto grados de 12 escuelas de educación elemental. Los datos se presentaron según el sexo y el nivel socioeconómico. Los niños de escuelas públicas $(n=219)$ se consideraron de nivel socioeconómico bajo (NSEB) y los de escuelas privadas $(n=230)$ como de nivel socioeconómico alto (NSEA). El consumo de frutas y vegetales en la dieta de cada estudiante se determinó a partir de un recordatorio de 24 horas mediante registros pictóricos y entrevistas personales. Se tabularon todos los alimentos que contenían frutas o vegetales (incluidas las bebidas). La frecuencia del consumo de frutas y vegetales se calculó a partir de las veces que se mencionó el consumo de una fruta o un vegetal y se evaluó el grado de adecuación nutricional mediante la comparación de los valores medios y medianos de cada grupo con el consumo diario recomendado por la OMS (400 g). Se utilizaron las directivas de exclusión del Fondo Mundial para las Investigaciones contra el Cáncer (WCRF) para estimar la contribución de las frutas y vegetales al aporte energético total.

Resultados. De los 247 diferentes alimentos identificados, 93 (37,7\%) contenían una fruta o un vegetal. Del los 6512 registros, 637 contenían alguna fruta y 701 algún vegetal. Aunque el consumo medio de frutas y vegetales fue de 461,3 g (desviación estándar $= \pm 332,5 \mathrm{~g})$, más de la mitad $(56,3 \%$ ) de los estudiantes tenían un consumo por debajo de los $400 \mathrm{~g}$ diarios recomendados. Se estimó que las frutas y vegetales contribuían en 21,2\% al aporte energético total en los niños de NSEA y en 19,1\% en los de NSEB.

Conclusiones. Estos resultados demuestran el inadecuado consumo de frutas y vegetales en la muestra estudiada. Para cumplir con las recomendaciones internacionales se necesitan intervenciones que promuevan el consumo de frutas y vegetales.

Frutas, vegetales, política nutricional, evaluación nutricional, nutrición en salud pública, nutrición del niño, Guatemala.

\section{Principios de orientación para la alimentación complementaria del niño amamantado}

Adquiera esta publicación por medio de la librería en línea de la OPS: http://publications.paho.org; correo electrónico: paho@brightkey.net; Fax: (301) 209-9789; Oficina de país de la OPS/OMS

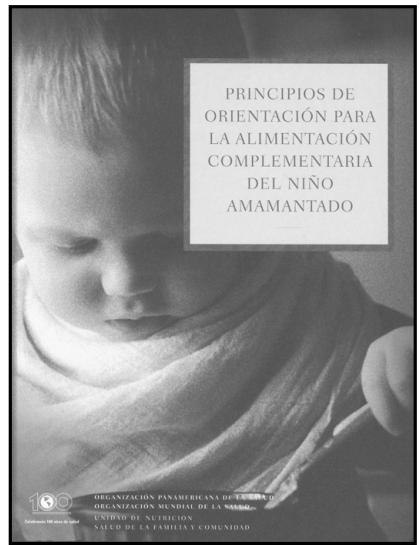

2003, 35 pp.

ISBN: 9275324603

US\$ 10.00 en América

Latina y el Caribe/

US\$14.00 en el resto del mundo

Código: OT 194 